\title{
Research on the river shrimps of the genus Macrobrachium (Bate, 1868) (Decapoda: Caridea: Palaemonidae) with known or potential economic importance: strengths and weaknesses shown through scientometrics
}

\author{
Olimpia Chong-Carrillo ${ }^{1}$, Fernando Vega-Villasante ${ }^{1}$, Ricardo Arencibia-Jorge ${ }^{2}$ \\ Shehu L. Akintola ${ }^{3}$, Layla Michán-Aguirre ${ }^{4}$ \& Fabio G. Cupul-Magaña ${ }^{5}$ \\ ${ }^{1}$ Laboratorio de Acuicultura Experimental, Centro de Investigaciones Costeras \\ Universidad de Guadalajara, Puerto Vallarta, CP 48280, Jalisco, México \\ ${ }^{2}$ Centro Nacional de Investigaciones Científicas, Playa La Habana, CP 10600, Cuba \\ ${ }^{3}$ Fisheries Department, Lagos State University, PMB 0001, LASU, Ojo, Lagos, Nigeria \\ ${ }^{4}$ Laboratorio de Cienciometría, Información e Informática en Ciencias Biológicas \\ Departamento de Biología Comparada, Facultad de Ciencias, UNAM \\ Coyoacán, Distrito Federal, CP 04510, México \\ ${ }^{5}$ Laboratorio de Artrópodos, Centro Universitario de la Costa, Universidad de Guadalajara \\ Puerto Vallarta, CP 48280, Jalisco, México \\ Corresponding author: Fernando Vega-Villasante (fernandovega.villasante@gmail.com)
}

\begin{abstract}
This study revealed that the scientific interest in the genus Macrobrachium was not restricted to a biological point of view, but included also social and economic aspects. Many species of the genus are subject of traditional fisheries and culture worldwide. Several research groups across the globe have developed projects in various subject areas on commercial or non-commercial native species of this genus. This investigation aimed to contribute to the development of the genus Macrobrachium research through a scientometric study. The study was based on publications (1980 to 2013) registered in the following databases: Biological Abstracts, ISI Web of Science, SciELO Citation Index, BioOne, Science Direct, Scopus, and Redalyc. A total of 2165 publications on Macrobrachium in the last 33 years were included in this analysis. The themes that yielded most posts were related to culture, nutrition/feeding, and genetics with almost $60 \%$ of the total. Publications concerning $M$. rosenbergii represented more than $60 \%$ of the total with the remaining $40 \%$ encompassing 22 other species. Analysis performed by geographical regions evidenced that Latin America produced $23 \%$ of the publications, South Asia 22\%, and East Asia 16\%. Brazil generated 65\% of the percentage mentioned for the Latin American region. It is necessary to strengthen research on topics of basic biology, especially those of native species. This will allow rapid progress in the generation of production technologies sustained by a solid biological knowledge base.
\end{abstract}

Keywords: native species, river shrimps, Macrobrachium, research, scientometrics.

Investigaciones sobre camarones de río del género Macrobrachium (Bate, 1868) (Decapoda: Caridea: Palaemonidae) con importancia económica conocida o potencial: fortalezas y debilidades mostradas a través de la cienciometría

\footnotetext{
RESUMEN. El interés científico por las especies del género Macrobrachium no ha sido sólo desde el punto de vista biológico, sino también económico y social. Muchas de sus especies son objeto de pesquerías tradicionales y cultivo. Diversos grupos de investigación del mundo han realizado trabajos sobre temáticas del conocimiento de especies nativas comerciales o no-comerciales. El presente trabajo pretende contribuir al desarrollo de la investigación del género Macrobrachium mediante análisis cienciométrico. Este estudio se basó en las publicaciones registradas en las siguientes bases de datos desde 1980 a 2013: Biological Abstracts, ISI Web of Science, SciELO Citation Index, BioOne, Science Direct, Scopus y Redalyc.
}

Corresponding editor: Ingo Wehrtmann 


\begin{abstract}
El número total de publicaciones sobre Macrobrachium en los 33 años analizados fue de 2165. Las temáticas que más publicaciones mostraron (60\% del total registrado) fueron las relacionadas con el cultivo, nutrición/alimentación y genética. Solo de M. rosenbergii se ha publicado más del $60 \%$ del total, el restante $39 \%$ de las publicaciones corresponde a 22 especies. El análisis por regiones geográficas puso en evidencia que Latinoamérica genera el 23\%, Asia del Sur 22\% y Asia Oriental 16\% de los trabajos publicados. Sólo Brasil genera el $65 \%$ del total de Latinoamérica. Es necesario reforzar la investigación dirigida a temáticas de biología básica sobre todo en las especies nativas. Esto permitirá avanzar más rápidamente en la generación de tecnologías de producción sustentadas en una base sólida de conocimiento biológico.
\end{abstract}

Palabras clave: especies nativas, camarones de río, Macrobrachium, investigación, cienciometría.

\section{INTRODUCTION}

Among the suborder Caridea, the family Palaemonidae includes 36 genera (Holthuis, 1952). Macrobrachium (Bate, 1868) (De Grave et al., 2008) constitutes the most diverse genus among the palaemonids, with at least 238 species distributed in tropical and subtropical streams and rivers around the world (Bauer, 2013). These shrimps are colloquially called prawns, acamayas, cauque, langostino or shrimp, depending on the region in which they are found (García-Guerrero et al., 2013).

The scientific interest in the genus Macrobrachium is not limited to a biological point of view, but also includes social and economic aspects. Many of these species are subject of traditional fisheries and culture (García-Guerrero et al., 2013). According to New (2009), production of shrimp reaches hundreds of thousands of tons per year, most of which are $M$. rosenbergii (De Man, 1878), which is originally from Asia. This species known as "Malaysian shrimp" or "giant river prawn" has been the most studied one, and its farming production technology has been exported to many countries outside their original distribution area.

Since 1980, when the first meeting in Thailand on the culture of $M$. rosenbergii was held, there has been increased scientific research directed towards establishing optimal conditions for controlled production of this species as well as native Macrobrachium species of economic importance (New \& Nair, 2012). Although other native species have been studied, knowledge about them has not matched that on $M$. rosenbergii. Several research groups have developed works in various areas on commercial or noncommercial native species. Currently, there are no studies showing how research has evolved concerning this important genus of decapods, the interests of research groups and countries, and the knowledge areas, which remain poorly understood for most of the species.

According to Hess (1997) scientometrics can be defined as the "quantitative study of science, communication in science, and science policy". Therefore, this study aimed to contribute to the development of research on the genus Macrobrachium, through a scientiometric analysis of scientific papers published and archived in various databases in the past three decades. In particular, this investigation has led to highlighting species with clear or potential economic value.

\section{MATERIALS AND METHODS}

The study, carried out according to the methodology of Michán \& Llorente-Bousquets (2010), included publications from 1980 to 2013 and registered in the following databases: Biological Abstracts, ISI Web of Science, SciELO Citation Index, BioOne, Science Direct, Scopus and Redalyc. In particular the Latin American databases (SciELO and Redalyc) were considered since they included some journals not compiled on commercial international databases. These omissions could cause a significant bias in the final results. In each of the databases all records containing the word Macrobrachium in the title, abstract, and keywords fields were searched. The records were collected from databases and systematized in a particular database organized with the aid of the EndNote X7 ® (Thomson Reuters $\left.{ }^{\circledR}\right)$ software. The data were subsequently validated and standardized, selecting the items that addressed species with known or potential economic importance. Analysis was then carried out by the following categories:

i) Theme: words in this selection were adjusted to include: farming, nutrition/feeding, genetics, reproduction, ecology, physiology, pathology, taxonomy, and behavior;

ii) Species: all species of the genus Macrobrachium that appear in any scientific document;

iii) Countries: the entire world is covered both by region and by individual countries;

iv) Authors: the most prolific authors were recorded;

v) Institutions: universities, research centers, and others that have made major contribution to the study of this genus. 
The data sets obtained by this process were transferred to Excel $^{\circledR}$ spreadsheets $\left(\right.$ Microsoft ${ }^{\circledR}$ ) for further analysis.

\section{RESULTS}

The total number of publications concerning Macrobrachium in the 33 years under review and within the above-mentioned terms was 2165 . The lowest number of publications was in the $80^{\prime}$ and showed a stable trend. A significant increase was observed in the early 90', particularly during the second half of this decade; and the trend of increasing number of publications continued up to 2013 (Fig. 1).

The number of publications per subject per decade is shown in Fig. 2. The themes that yielded most posts were related to the culture (947), nutrition/feeding (422), and genetics (262). Considerably fewer publications referred to the other research areas. The three above-mentioned most popular topics showed an upward trend with steep slopes, where publications about culture stood out. However, subjects with the lowest number of publications also showed an increase but less pronounced.

When the total number of publications by subject was analyzed, it was noted that those related to culture and nutrition/feeding accounted for more than $60 \%$ of the total. The remaining subjects shared the other $40 \%$ out of which genetics was about $12 \%$. Macrobrachium rosenbergii comprised more than $60 \%$ of the total publications (Fig. 3). The other 22 species made up approximately $40 \%$ of the published studies in the databases. M. amazonicum (Heller, 1862) and $M$. nipponense (De Haan, 1849) represented 6.2\% and $6.5 \%$ respectively, of the published literature. $M$. amazonicum was the most studied and analyzed species in the American region followed by M. carcinus (Linnaeus, 1758) and M. acanthurus (Wiegman, 1836) with $14 \%$ and $13 \%$ respectively. These three species accounted for $56 \%$ of the published literature. The remaining nine Latin American species accounted for 44\%: M. olfersii $10 \%, M$. borelli $9 \%, M$. tenellum and M. americanum 5\% each, $M$. jelskii and M. ohione 4\% each, M. heterochirus and M. crenulatum 3\% each, and M. birai with $1 \%$.

The country analysis (Fig. 4) revealed that only four of the 21 contributing countries provided more than $50 \%$ of published papers. India led the countries with almost $20 \%$, followed by Brazil with $14.4 \%$, United States of America with $10.4 \%$, and China with $9.0 \%$. The analysis by region demonstrated that Latin America produced 23\% of the papers published, South Asia 22\%, and East Asia 16\%. Therefore, these three regions accounted for more than $50 \%$ of publications concerning Macrobrachium. In Latin America, Brazil produced the majority of publications $(65 \%)$, followed by Mexico (19\%). The ten authors with most scientific publications regarding the genus are indicated in Fig. 5. Universities and research centers that are mentioned in

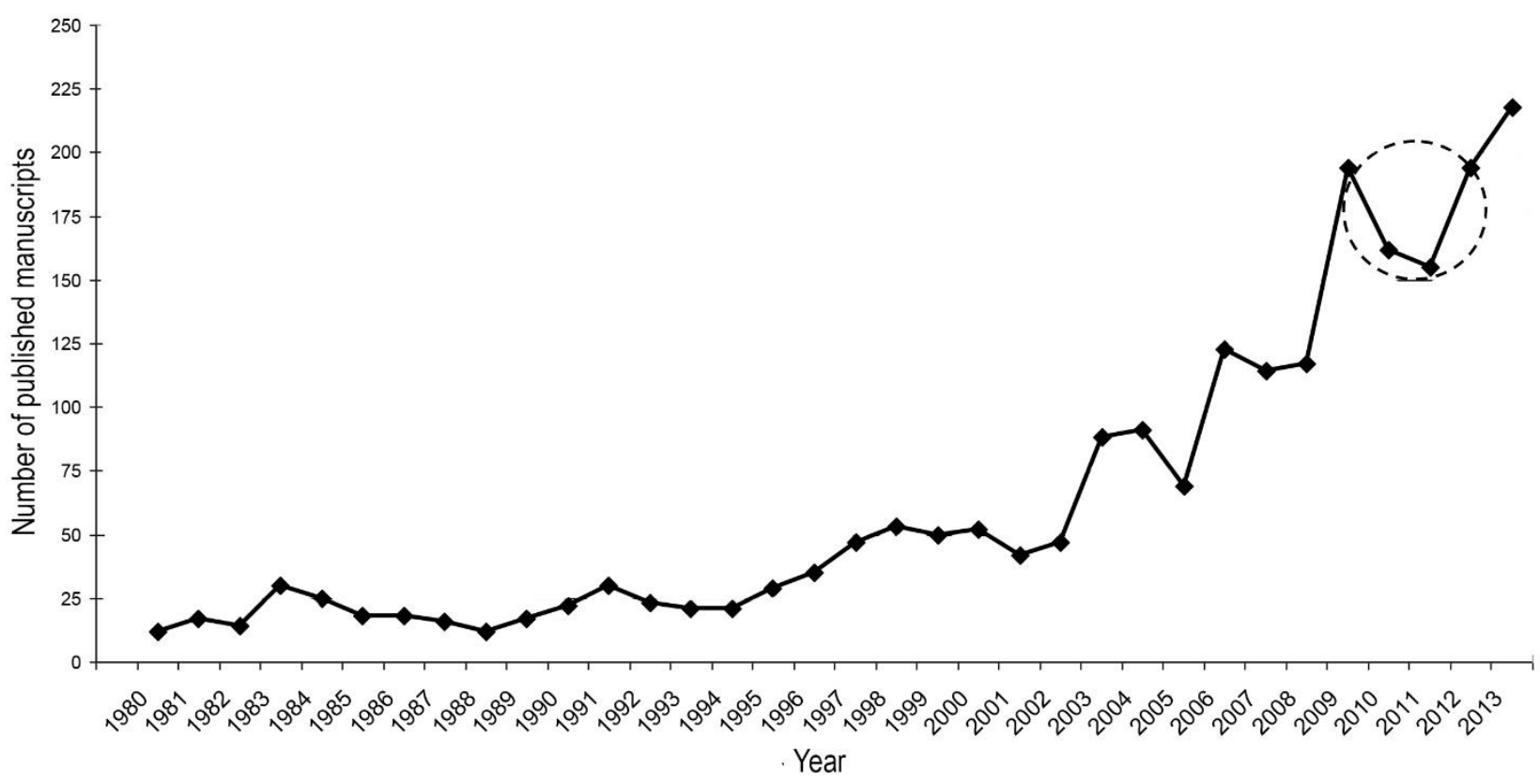

Figure 1. Number of manuscripts published worldwide concerning the genus Macrobrachium in 33 years. The dashed circle indicates the unusual decline in scientific publications regarding Macrobrachium, probably caused by the global economic crisis. 


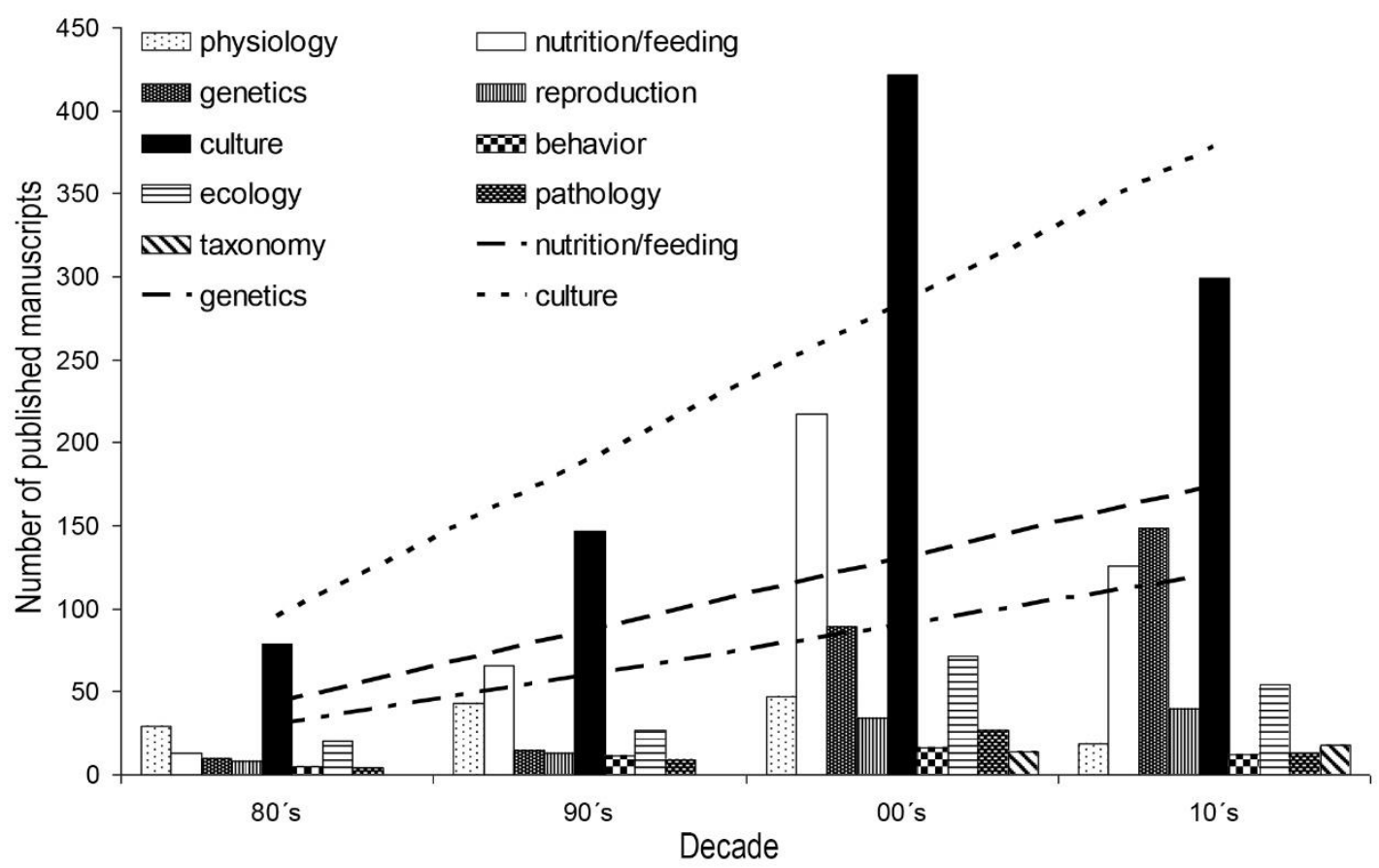

Figure 2. Number of manuscripts published per decade regarding the genus Macrobrachium by subject.

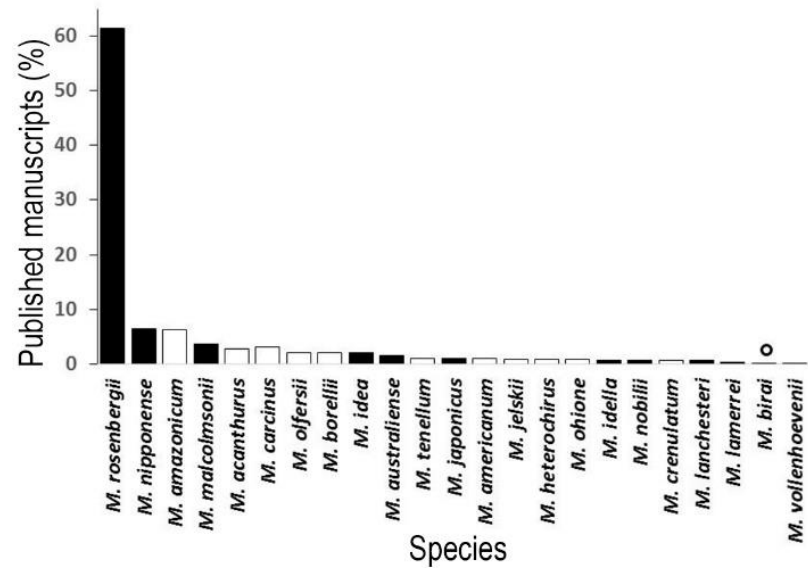

Figure 3. Worldwide publications concerning the genus Macrobrachium by species. White bars and circle represent the American species.

the literature are shown in Fig. 6. The University of São Paulo is the institution that produced most of the publications concerning economically important prawns of the genus Macrobrachium.

\section{DISCUSSION}

As far as we know, the only previous evaluation of the scientific literature concerning the genus Macrobrachium was published by García-Guerrero et al. (2013); these authors discussed 195 scientific papers

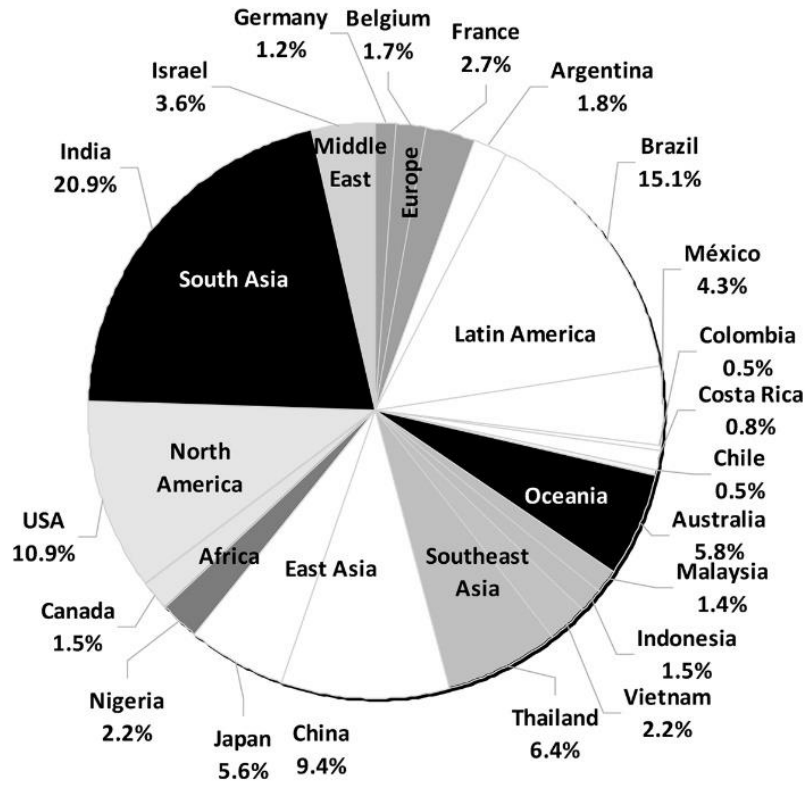

Figure 4. Publications about the genus Macrobrachium by geographical area and country.

regarding Latin American species of the genus. Their results agreed with those presented in this study and revealed that scientific articles published on grow-out techniques comprised the highest percentage $(21 \%)$. However, their findings about the number of publications focused on nutrition and genetics differed from the trends detected in the present study. In the above- 


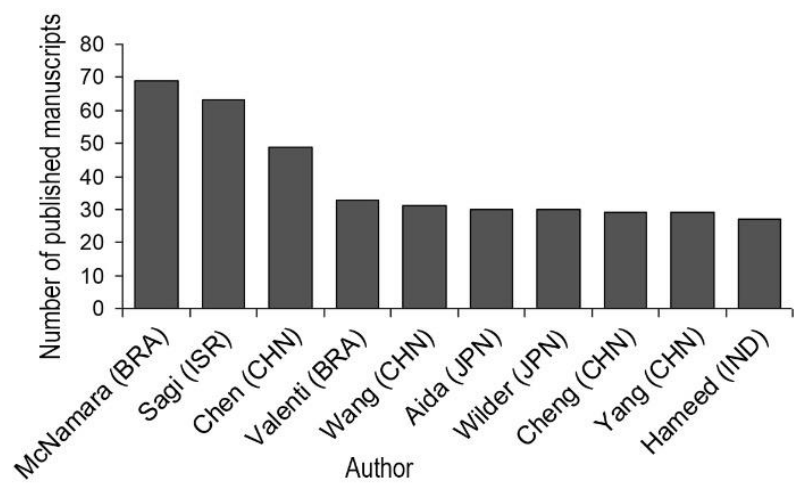

Figure 5. Top ten authors of Macrobrachium publications worldwide.

mentioned study (García-Guerrero et al., 2013), the authors found that subjects regarding physiology (15\%), reproduction (9\%), and phylogeny, taxonomy and systematics (9\%) showed the highest percentage of published results, while nutrition and genetics were represented by $5 \%$ and $2 \%$ of the total, respectively. These findings differ from those of the present study where nutrition and genetics are two of the three main themes covered by published manuscripts. Nevertheless, the study of García-Guerrero et al. (2013) included only Latin American species of Macrobrachium whereas our study comprised species on a global level including $M$. rosenbergii with a high number of publications. Despite these differences between both studies, culture was by far the topic that generated the highest number of scientific publications.

After the conference on "Giant Prawn", held in Thailand in 1980, a slight increase in the number of publication concerning the genus was observed, but scientific production remained stable during that decade. The largest increase was observed in the early '90s. This phenomenon is probably due to the development of new technologies, most of them related to culture innovations, feed formulations, diagnosis and treatments of diseases, and reproduction techniques (Chong-Carrillo et al., unpublished data). We assume that the 80 's had a scientific production stimulated by the above-mentioned meeting, and investigations regarding developing production technologies were intense but had not yet resulted in publications. By the 90's, new research groups began to consolidate their studies towards production of culture techniques. However, scientists also published their findings about other scientific aspects working with native species as well as non-native species (for example Brazilian groups led by John C. McNamara and Wagner C. Valenti, as well as many Indian groups working on $M$. rosenbergii).
The explosive growth of scientific production noticed from the first part of the 90's has not slowed until recently. Although there have been declines in the published scientific production as manifested in 2010 and 2011, only two years after the onset of the global economic crisis, there was a remarkable rebound in 2009, probably due to the inertia of scientific production that had already been carried out in previous years. The decrease that occurred in 2010 and 2011 might be associated with the effects of the global economic crash, which started in 2008 and lasted until 2011, with deleterious effects in all areas of the world development, including science and technology country budgets (Chinn, 2010). Only three years later the trend of scientific production got back to previous levels.

Revising the topics addressed in the scientific literature, it is obvious that the highest number of these publications referred to culture aspects. Studies of culture techniques, nutrition, and genetics were certainly those topics related to developing a more efficient production. Noticeable was the fact that genetics was also an emerging topic in the field of scientific publications on Macrobrachium. The growth of genetic themes started at the beginning of the 90's, ten years later than the other two most popular themes. If production trends remain as they are today, we are likely to see a gradual overlap in the number of publications of the three main topics. However, the remaining topics (ecology, physiology, reproduction, pathology, taxonomy and behavior), which might provide the biological basis for the other three most popular themes, showed a poor increase in publications especially with regard to native species.

FAO (2012) has repeatedly mentioned the need for increased research on native species before introducing alien species. This suggestion is particularly emphasized in its report: State of Fisheries and Aquaculture 2012 (Sofia 2012 Report; FAO, 2012). Although various research groups worldwide have addressed this advice, it has not influenced the ongoing increase of scientific publications based on studies regarding $M$. rosenbergii. Research groups from Asia, Oceania, USA, and Israel supported the scientific production about this species. While this trend has not been reversed, many countries have developed studies on native species in actual or potential farming. Noteworthy examples are the groups in Brazil, with the largest number of publications on native species, particularly concerning $M$. amazonicum. Another already cultivated species that has produced a lot of publications is $M$. nipponense in China and $M$. malcomsonii (H. Milne-Edwards, 1844) in India. In Latin America, there are also efforts on research and 


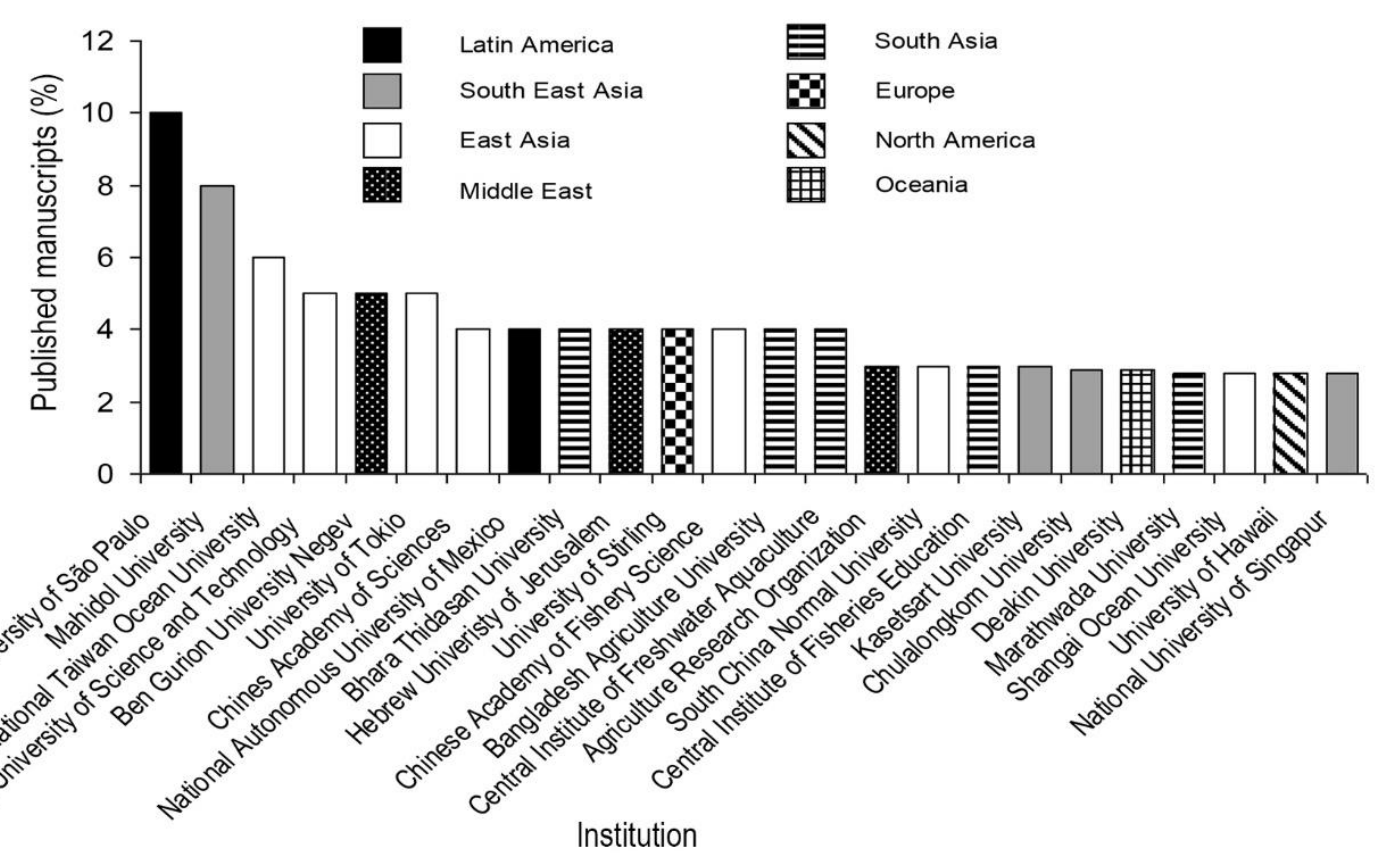

Figure 6. Top global institutions generating scientific publications concerning the genus Macrobrachium.

publications about native species: Brazil has provided a significant number of publications regarding $M$. amazonicum, as well as about species such as $M$. acanthurus, M. olfersii (Wiegmann, 1836), and $M$. carcinus, among others. Argentine groups have made significant progress in scientific knowledge about $M$. borellii (Nobili, 1896), especially in the areas of basic biology, placing this species as one of the most studied ones in the Americas. Great research efforts, though scattered, are being made in Mexico with M. tenellum (Smith, 1871), M. americanum (Bate, 1868), and $M$. carcinus.

Brazil has devoted considerable more human and funding resources compared to other countries in the region: in 2011 Brazil spent $1.6 \%$ of its gross domestic product (GDP) in science and technology, a considerably higher percentage when compared to $0.62 \%$ of Argentina, $0.48 \%$ of Costa Rica, $0.46 \%$ of México, $0.42 \%$ of Chile, and $0.18 \%$ of Colombia (World Bank, 2014). It is thus clear that the higher the support for science and technology, the higher is the capacity for knowledge generation; a premise valid in the case of Macrobrachium research.

Worldwide, the ten most productive scientists regarding Macrobrachium research include two Brazilians (John C. McNamara and Wagner C. Valenti), Amir Sagi from Israel (4.4\% of GDP in science and technology), and Jian Chu Chen from China (1.8\% of GDP in science and technology), among others. Again, Brazil shows a considerable ad- vantage compared to other countries with regard to institutions and centers studying Macrobrachium. The University of São Paulo (USP) stood out as the foremost institution worldwide concerning scientific publications about Macrobrachium. According to Scimago Institutions Rank (SIR) 2013, the USP ranked 12 in the overall list, and first in the 2013 Iberoamerican SIR.

The results shown in the Figures 5 and 6 were obtained solely from the ISI database because it remained the most important global reference in the analysis and evaluation of published science. We are aware that the inclusion of other databases may modify results obtained in the present investigation.

The scenario described in this study allowed us to conclude that there are clear conclusions regarding research about Macrobrachium in the world: i) scientific publications on Macrobrachium is on the rise worldwide; ii) there is a strong scientific community that focuses its research efforts on this genus; iii) main topics address and are intended to resolve issues of growing and breeding; iv) there is a trend of increasing research on native species; v) compared to developed countries, emerging countries are devoting more efforts to conduct research concerning Macrobrachium; vi) renowned universities and research centers globally support scientific productivity regarding Macrobrachium.

There are, however, also weaknesses: i) research is mainly directed to $M$. rosenbergii, while the number of 
studies on native species remains low; ii) the basic themes that can sustain a solid understanding of the biology of native species are not addressed with the same intensity as those directed towards growth; iii) only a few of the emerging countries maintain scientific production; iv) although Latin America is the most productive region, few universities and research centers support the scientific productivity regarding Macrobrachium; v) with the exception of Brazil, apparently there is no concerted effort in the remaining Latin American countries to increase their knowledge on native Macrobrachium species; and v) only two authors and two Latin American universities appear as main publication generators of Macrobrachium literature. It is necessary to strengthen research on topics of basic biology especially of native species. This will allow a rapid progress in the generation of production technologies sustained by a solid biological knowledge base. Also, it will help setting priorities for the advancement of aquaculture at local and regional levels as well as the protection of indigenous natural resources. There is also a need to increase research efforts on culture of local species with commercial potential to replace or compete with the production of $M$. rosenbergii. Governments and universities in emerging countries should devote more resources to study the ecology and other basic subjects of native Macrobrachium species.

\section{ACKNOWLEDEGMENTS}

This work was carried out thanks to a doctoral fellowship from the Consejo Nacional de Ciencia y Tecnología (CONACYT) from México, awarded to the first author of this manuscript. The authors wish to thank the anonymous reviewers of this manuscript, since their suggestions significantly improved its quality. Special thanks to Dr. Ingo Wehrtmann for his contribution and patience as Associate Editor.

\section{REFERENCES}

Bauer, R. 2013. Amphidromy in shrimps: a life cycle between rivers and the sea. Lat. Am. J. Aquat. Res., 41: 633-650.

Chinn, L.W. 2010. The global state of science funding. ASBMB today. May issue: 18-19. [http://www.asbmb. org/uploadedFiles/ASBMBToday/Content/Archive/A SBMBToday-2010-05.pdf]. Reviewed: 7 May 2015.
De Grave, S., Y. Cai \& A. Anker. 2008. Global diversity of shrimps (Crustacea: Decapoda: Caridea) in freshwater. Hydrobiología, 595: 287-293.

Food and Agriculture Organization (FAO). 2012. Informe Sofía. El estado mundial de la pesca y la acuicultura. Departamento de Pesca y Acuicultura de la FAO. Roma. [http://www.fao.org/docrep/016/i2727s/i272 7s.pdf]. Reviewed: 12 March 2015.

García-Guerrero, M.U., F. Becerril-Morales, F. VegaVillasante \& L.D. Espinosa. 2013. Los langostinos del género Macrobrachium con importancia económica y pesquera en América Latina: conocimiento actual, rol ecológico y conservación. Lat. Am. J. Aquat. Res., 41: 651-675.

Hess, D.J. 1997. Science studies: an advanced introduction. New York University, New York, 206 pp.

Holthuis, L.B. 1952. A general revision of the Palaemonidae (Crustacea: Decapoda: Natantia) of the Americas. II. The subfamily Palaemoninae. Allan Hancock Found, Publ. Occas. Pap., 12: 1-396.

Michán, L. \& J. Llorente-Bousquets. 2010. Bibliometría de la sistemática biológica sobre América Latina durante el siglo XX en tres bases de datos mundiales. Rev. Biol. Trop., 58: 531-545.

New, M. 2009. History and global status of freshwater prawn farming. In: M.B. New, W.C. Valenti, J.H. Tidwell, L.R. D'Abramo \& M.N. Kutty (eds.). Freshwater prawns: biology and farming. WileyBlackwell, New York, 1: 1-11.

New, M. \& M. Nair. 2012. Global scale of freshwater prawn farming. Aquacult. Res., 43: 960-969.

World Bank. 2014. Science and Technology. Gross Domestic Product. [http://data.worldbank.org/topic/ science-and-technology]. Reviewed: 2 May 2014. 